\title{
Evaluation of Copper Oxide Nanoparticles Toxicity Using Chlorophyll $a$ Fluorescence Imaging in Lemna gibba
}

\author{
François Perreault, ${ }^{1}$ Abdallah Oukarroum, ${ }^{1}$ Laura Pirastru, ${ }^{1}$ Louka Sirois, ${ }^{1}$ William Gerson \\ Matias, ${ }^{2}$ and Radovan Popovic ${ }^{1}$ \\ ${ }^{1}$ Department of Chemistry, University of Quebec in Montreal, P.O. Box 8888, Station Centre-Ville, Montreal, QC, Canada H3C 3P8 \\ ${ }^{2}$ Laboratório de Toxicologia Ambiental (LABTOX), Departamento de Engenharia Sanitária e Ambiental, \\ Universidade Federal de Santa Catarina, Campus Universitário, 88040-970 Florianópolis, SC, Brazil
}

Correspondence should be addressed to Radovan Popovic, popovic.radovan@uqam.ca

Received 19 June 2010; Accepted 17 August 2010

Academic Editor: Naohiro Kato

Copyright (C) 2010 François Perreault et al. This is an open access article distributed under the Creative Commons Attribution License, which permits unrestricted use, distribution, and reproduction in any medium, provided the original work is properly cited.

\begin{abstract}
Copper oxide nanoparticles ( $\mathrm{CuO} \mathrm{NPs}$ ), used in antifouling paints of boats, are released in the environment and can induce toxicity to aquatic organisms. In this report, we used chlorophyll $a$ fluorescence imaging to evaluate CuO NPs toxicity in Lemna gibba. This approach allowed to evaluate the differential effect of $\mathrm{CuO}$ NPs on photosynthesis of whole L. gibba plants. Exposure to 0.1 to $0.4 \mathrm{~g} / \mathrm{L} \mathrm{CuO} \mathrm{NPs} \mathrm{during} 48 \mathrm{~h}$ induced strong inhibition of photosynthetic processes resulting in a decrease of plant growth. By using fluorescence imaging, different photosynthetic parameters were evaluated simultaneously in microplate conditions. Imaging of $F_{O}$ fluorescence yield showed the decrease of leaf photosynthetic active surface for whole plants exposed to CuO NPs. This method showed that CuO NPs inhibited photosystem II maximal, photosystem II operational quantum yields, and photochemical quenching of fluorescence associated with electron transport. Nonphotochemical fluorescence quenching as an indicator of energy dissipation not used in photosynthesis was shown to be increased by the effect of CuO NPs. Such approach in microplate conditions provides synchronous high repetition measurements for numerous plants. This study may give a reliable methodological approach to evaluate toxicity risk of NPs in aquatic ecosystems.
\end{abstract}

\section{Introduction}

Development of nanotechnologies in the recent decades has led to the widespread use of nanomaterials in all kinds of common industrial and medical applications [1]. The use of nanomaterials may represent important toxicological risks because of the difficulty to evaluate the possible toxic effects of such pollutants. The mechanism by which nanomaterials may alter biological systems is dependant to nanomaterial's size, shape, composition, and surface properties [2]. Due to the fast growth of the nanotechnology domain, aquatic ecosystems may be contaminated by nanosized pollutants such as metallic nanoparticles (NPs), which are one of the main types used at large scale for industrial applications [3]. Toxicological properties of metallic NPs are difficult to evaluate because toxicity is dependant on both the nanoparticulate form and the toxic metal ions which can be released by the NPs $[4,5]$. In addition, it has been found that the organic compounds used in NPs' synthesis can induce by themselves toxic effects [6]. For these reasons, it has been emphasized that NPs' toxicity is complex and many toxicological aspects still remain to be further investigated [7].

The use of NPs such as copper oxide (CuO) NPs in antifouling paints of boats represents an important source of NPs contamination of aquatic ecosystems. These paints consist of a polymeric film made mostly of acrylic and styrenic monomers covering copper oxides NPs [8]. This kind of paint may release copper species in the environment [9]. Decomposition of these paints may release copper under soluble ionic forms or as NPs, both of which can be toxic to aquatic life $[10,11]$. Aquatic photosynthetic 
organisms represent the main source of biomass in the aquatic trophic chain and these organisms are very sensitive to the effects of copper species. It has been reported that copper may induce strong inhibition of photosynthetic electron transport mboxprocesses and oxidative stress at cellular level $[12,13]$. We reported recently that $\mathrm{CuO}$ NPs, having a core of $\mathrm{CuO}$ NPs and a shell of polyacrylic acid (PAA), were found to be very toxic to unicellular algae, causing inhibition of PSII electron transport capacity in Chlamydomonas reinhardtii cultures [11]. However, toxicity of $\mathrm{CuO}$ NPs was not evaluated in other photosynthetic organisms such as higher aquatic plants.

For the evaluation of pollutant's toxicity, the measure of chlorophyll (Chl) a fluorescence yield was found to be a sensitive methodological approach $[14,15]$. Chl $a$ fluorescence induced by light absorption represents a part of the dissipated light energy not used for Photosystem II (PSII) photochemistry and electron transport activity (for a review, see [16]). It is well known that when photosynthetic events related to biochemical or physiological processes are inhibited, the yield and kinetics of dissipated fluorescence are significantly changed [17]. Therefore, Chl $a$ fluorescence can serve as a reliable, noninvasive indicator of photosynthetic processes in plants. The pulse-amplitude-modulation (PAM) fluorometric approach can provide useful information concerning photosynthetic electron transport and energy dissipation processes associated with PSII and PSI activity. Using the PAM approach, the yield of variable Chl $a$ fluorescence as a measure of the PSII-PSI electron transport was frequently used to determine the toxic effects of metals and herbicides [18-20]. Parameters linked to PSII electron transport capacity $\left(F_{V} / F_{M}, F_{V}^{\prime} / F_{M}^{\prime}\right)$, photochemical energy dissipation $(\mathrm{qP})$, and nonphotochemical quenching of fluorescence ( $q N, \mathrm{NPQ})$ are sensitive bioindicators of toxicity in plants and algae $[14,21]$. Recently, the development of Chl $a$ fluorescence imaging system allowed for rapid and simultaneous measurements of a large number of samples. This approach was used for fast screening of plants mutants [22] and to evaluate different pathogen's effect in higher plants [23]. Using microplate bioassays, Chl $a$ fluorescence imaging was used for the evaluation of herbicides toxicity in algae and higher plants [24-26]. However, it is not known how $\mathrm{CuO}$ NPs may induce toxic effects on PSII photosynthetic electron transport and energy dissipation processes in higher plants.

In this paper, we investigated the use of Chl $a$ fluorescence imaging for rapid evaluation of CuO NPs' toxicity in the aquatic higher plant Lemna gibba in microplate conditions. In order to differentiate the effect of $\mathrm{CuO}$ NPs, we also investigated the possible toxic effects of dissolved ionic copper and polyacrylic acid (PAA), used for NPs' coating. Additionally, Chl $a$ fluorescence kinetic was analysed using the PAM fluorometric approach to provide sensitive parameters useful to determine the toxic effect of $\mathrm{CuO}$ NPs on photosynthetic processes. Chl $a$ fluorescence imaging was used to determine the change of such photosynthetic parameters in whole $L$. gibba plants exposed to CuO NPs' effect. This approach was evaluated concerning its application in ecotoxicological risk assessment.

\section{Materials and Methods}

2.1. Biological Material. L. gibba was obtained from Canadian Phycological Culture Centre (formerly UTCC \#310). Plants were grown in an inorganic culture medium as described by [27], in a growing chamber (CONVIRON, Controlled Environments Limited, Winnipeg, Manitoba, Canada), with a $16 \mathrm{~h} / 8 \mathrm{~h}$ light/dark photoperiod. Illumination was of $100 \mu \mathrm{E} \mathrm{m}^{-2} \mathrm{~s}^{-1}$ provided by cool white fluorescent lamps (Sylvania GRO-LUX F40/GS/WS, Drummondville, Canada). Temperature was kept at $24^{\circ} \mathrm{C}$.

2.2. CuO NPs Preparation and Characterization. Detailed synthesis of $\mathrm{CuO}$ NPs can be found in [11, 28]. Briefly, $4 \mathrm{~g}$ of $\mathrm{CuO}$, provided by MTI Corporation (Richmond, CA, USA), and $110 \mathrm{mg}$ of polyacrylic acid were prepared by RAFT polymerization mediated with trithiobenzyl carbonate and $20 \mathrm{~mL}$ of nanopure water. The samples were placed in $50 \mathrm{~mL}$ beakers in an ice bath. The mixture was stirred with a magnetic stir bar and sonicated for $3 \mathrm{~min}$ with a sonicator (VibraCell $400 \mathrm{~W}$ ) equipped with a microtip. Under these conditions, an off-white dispersion of $\mathrm{CuO}$ in water was obtained. In a $250 \mathrm{~mL}$ round-bottom flask, $4.0 \mathrm{~mL}$ of styrene, $51.5 \mathrm{mg}$ of sodium dodecyl sulphate, and $20.1 \mathrm{~mL}$ of the $\mathrm{CuO}$ dispersion were slowly stirred and degassed for $30 \mathrm{~min}$ by sparging with argon. The mixture was heated at $80^{\circ} \mathrm{C}$. A solution containing three droplets of sodium hydroxide (30\%) and $40 \mathrm{mg}$ of $4,4^{\prime}$-azobis-4cyanovaleric acid in $20.2 \mathrm{~mL}$ of nanopure water was added continuously during $4 \mathrm{~h}\left(5 \mathrm{~cm}^{3} / \mathrm{h}\right)$ to the $\mathrm{CuO}$ dispersion. The use of the sodium hydroxide was to facilitate the dissolution of the initiator (carboxylic acid). The mixture was then kept at $80^{\circ} \mathrm{C}$ for $1 \mathrm{~h}$ in order to bring the reaction to completion. The reaction medium was analyzed by gravimetry ( $14.8 \%$ solids), thermogravimetric analysis (TGA, weight composition: $67 \%$ core, 33\% shell), and transmission electronic microscopy (TEM). TEM micrographs were obtained with a Tecnai 12 Biotwin microscope equipped with a W source $(80$ and $120 \mathrm{kV})$ and a 13 Mpixel Morada camera. The samples were obtained by depositing a dilute sample on a gold grid coated with a formvar film. No contrast agent was used. Using this approach, particle diameter, measured by TEM, was $81 \mathrm{~nm}$ (standard deviation $16 \mathrm{~nm}$ ) and shell thickness was $14 \mathrm{~nm}$ (for detailed data, see $[11,28])$.

2.3. Pollutant Treatments. For experiments, plants of L. gibba developed at the stage of three fronds (during exponential growth) were used. Plants were placed in a 24 well microplate, one plant per well, in $2 \mathrm{~mL}$ of culture media. To avoid evaporation of the media during treatment, the microplate was closed with a lid. On the microplate, plants were exposed in duplicates to $0.1,0.2$, and $0.4 \mathrm{~g} / \mathrm{L}$ of $\mathrm{CuO}$ NPs. For all concentrations of $\mathrm{CuO}$ NPs, a second treatment was done using only the dissolved ionic copper fraction present in the NPs treatments. To determine the total dissolved copper content of the NPs' treatments, NPs were removed from the treatment media by centrifugation 
and analyzed using atomic absorption spectroscopy. Measurements of dissolved copper were done before and after the $48 \mathrm{~h}$ of treatments and no differences in the dissolved copper content was found between the beginning and the end of the treatment $(p=0.33)$. These results indicate that NPs' coating effectively prevented the degradation of $\mathrm{CuO}$ NPs into ionic copper in the media. From this approach, determined dissolved copper content was $3.29 \pm 0.13,6.60 \pm$ 0.33 , and $13.16 \pm 0.63 \mathrm{mg} / \mathrm{L}$, for the $0.1,0.2$, and $0.4 \mathrm{~g} / \mathrm{L} \mathrm{CuO}$ NPs' concentrations, respectively. Dissolved ionic copper was added as $\mathrm{CuSO}_{4}$ to the treatment media. On the plate, a third treatment was composed of the PAA organic fraction of the $\mathrm{CuO}$ NPs that was used for NPs' coating. PAA was added to the treatment media according to the $67 \%-33 \%$ ratio of organic shell/inorganic core composition of the $\mathrm{CuO}$ NPs found in [28]. According to this ratio, PAA treatments were of $0.067,0.134$, and $0.268 \mathrm{~g} / \mathrm{L}$ for the $0.1,0.2$, and $0.4 \mathrm{~g} / \mathrm{L}$ $\mathrm{CuO}$ NPs concentrations, respectively. The disposition of the treatments on the experimental microplate is presented in Table 1.

2.4. Chl a Fluorescence Measurements. Chl a fluorescence kinetics were measured simultaneously in all samples at time 0,24 , and $48 \mathrm{~h}$ of treatments using the MAXIImaging PAM fluorometer system (Walz, Germany). For these measurements, the microplate was placed in the dark for 30 minutes to obtain equilibrium of PSII oxidoreduction state. Chl a fluorescence kinetic was measured according to $[29,30]$. The fluorescence $F_{O}$, which represents basal fluorescence yield from chlorophylls of light-harvesting complexes, was evaluated by using a modulated light with a low intensity $\left(1 \mu \mathrm{E} \mathrm{m}^{-2} \mathrm{~s}^{-1}\right)$ to avoid the reduction of PSII primary electron acceptor, $\mathrm{Q}_{\mathrm{A}}$. The maximal fluorescence yield, $F_{M}$, was induced by a short, saturating pulse of white light $\left(5000 \mu \mathrm{E} \mathrm{m}^{-2} \mathrm{~s}^{-1}, 0.8 \mathrm{~s}\right.$ duration), causing maximal reduction of PSII. The value of $F_{S}$ was determined at the steady state of variable fluorescence obtained when algal samples were exposed $(10 \mathrm{~min})$ to continuous actinic light $\left(100 \mu \mathrm{E} \mathrm{m}^{-2} \mathrm{~s}^{-1}\right)$. The maximal fluorescence yield, $F_{M}^{\prime}$, was determined by application of a saturating light $\left(5000 \mu \mathrm{E} \mathrm{m}^{-2} \mathrm{~s}^{-1}, 0.8 \mathrm{~s}\right.$ duration) at steady state of fluorescence when plants were exposed to continuous actinic light. The $F_{O}^{\prime}$ fluorescence yield, indicating the fluorescence yield when PSII reaction center was in open state at steadystate conditions, was determined as $F_{O}^{\prime}=F_{O} /\left(F_{V} / F_{M}+\right.$ $\left.F_{O} / F_{M}^{\prime}\right)$, according to [31]. The maximal PSII quantum yield, indicating efficiency of light energy transfer to primary acceptor $Q_{A}$, was determined as the ratio $F_{V} / F_{M}=\left(F_{M}-\right.$ $\left.F_{O}\right) / F_{M}$ [32]. According to [33], the operational quantum yield was determined as the ratio $F_{V}^{\prime} / F_{M}^{\prime}=\left(F_{M}^{\prime}-F_{S}\right) / F_{M}^{\prime}$, and the photochemical quenching value was evaluated as $\mathrm{qP}=\left(F_{M}^{\prime}-F_{S}\right) /\left(F_{M}^{\prime}-F_{O}^{\prime}\right)$ representing the photochemical energy conversion at PSII reaction centers when the primary acceptor $\mathrm{Q}_{\mathrm{A}}$ has been oxidized [29]. The fluorescence quenching which was not related to photochemistry of PSII was measured as the ratio $q N=1-\left(F_{M}^{\prime}-F_{O}^{\prime}\right) /\left(F_{M}-F_{O}\right)$ according to [34]. According to [35], the nonphotochemical quenching parameter was determined as the NPQ $=\left[F_{M}-\right.$ $\left.F_{M}^{\prime}\right] / F_{M}^{\prime}$.

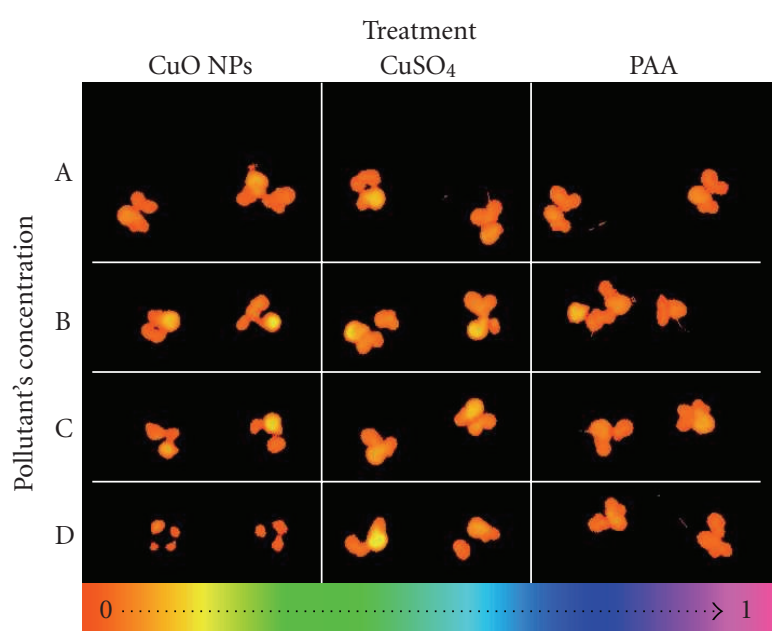

$F_{O}$ fluorescence value (relative)

FIGURE 1: The change of active photosynthetic surface in L. gibba whole plants exposed $48 \mathrm{~h}$ to different concentrations of $\mathrm{CuO}$ NPs, ionic copper $\left(\mathrm{CuSO}_{4}\right)$, and polyacrylic acid (PAA). The active photosynthetic surface was evaluated by imaging of the $F_{O}$ fluorescence yield for entire plant distributed in the microplate. Treatments' concentrations in the different rows (A, B, C, D) are distributed in the microplate according to Table 1 . The change of leaf area and leaf $\mathrm{Chl}$ distribution is indicated on the figure by the change of the size and shape of the fluorescence emission. Color scale on the bottom of the figure indicates the color associated with the relative value of $F_{O}$ fluorescence yield.

2.5. Data Analysis and Statistics. All treatments were done in duplicates on the microplate, and the experiment was repeated three times. Means and standard deviations were calculated for each treatment. Significant differences between control and exposed plants were determined by analysis of variance (ANOVA) and Tukey Honestly Significant Differences (HSD) test where $P$-value less than .05 was considered to be significant.

\section{Results and Discussion}

The effects of $\mathrm{CuO}$ NPs should be considered as a complex since NPs can go through a degradation process which can release other toxic products. Therefore, such secondary products of NPs' degradation should also be investigated in addition to the investigated NP form to better determine the effect closely associated with the interactions of NPs with cellular system. It has been shown that $\mathrm{CuO}$ NPs may release copper ions $\left(\mathrm{Cu}^{2+}\right)$ [36] which may induce itself toxic effects. It is known for copper ions to inhibit photosynthetic processes in Lemna minor [27]. On the other hand, acrylic acid has been indicated to induce toxic effects on algae and aquatic macrophytes [37]. However, in another recent report, polyacrylic acid (PAA) was shown to have no effect on the unicellular algae Chlamydomonas reinhardtii [11]. Therefore, by considering those effects, we investigated simultaneously the interactions of $\mathrm{CuO} \mathrm{NPs}$, copper ions (added as $\mathrm{CuSO}_{4}$ ), and PAA with photosynthetic physiological state of L. gibba. To determine the change of the active photosynthetic surface 
TABLE 1: Disposition of the different treatments on the microplate. Concentrations of 0.00 indicate control samples.

\begin{tabular}{|c|c|c|c|c|c|c|}
\hline \multirow{3}{*}{$\begin{array}{l}\text { Treatments } \\
\mathrm{A}\end{array}$} & \multicolumn{2}{|c|}{$\mathrm{CuO}$ NPs } & \multicolumn{2}{|c|}{ Ionic copper (CuSO4) } & \multicolumn{2}{|c|}{ Polyacrylic acid (PAA) } \\
\hline & $\mathrm{CuO}$ NPs & $\mathrm{CuO}$ NPs & $\mathrm{CuSO}_{4}$ & $\mathrm{CuSO}_{4}$ & PAA & PAA \\
\hline & $0.00 \mathrm{~g} / \mathrm{L}$ & $0.00 \mathrm{~g} / \mathrm{L}$ & $0.00 \mathrm{mg} / \mathrm{L}$ & $0.00 \mathrm{mg} / \mathrm{L}$ & $0.00 \mathrm{~g} / \mathrm{L}$ & $0.00 \mathrm{~g} / \mathrm{L}$ \\
\hline \multirow{2}{*}{ B } & $\mathrm{CuO}$ NPs & $\mathrm{CuO}$ NPs & $\mathrm{CuSO}_{4}$ & $\mathrm{CuSO}_{4}$ & PAA & PAA \\
\hline & $0.10 \mathrm{~g} / \mathrm{L}$ & $0.10 \mathrm{~g} / \mathrm{L}$ & $3.29 \mathrm{mg} / \mathrm{L}$ & $3.29 \mathrm{mg} / \mathrm{L}$ & $0.07 \mathrm{~g} / \mathrm{L}$ & $0.07 \mathrm{~g} / \mathrm{L}$ \\
\hline \multirow{2}{*}{$\mathrm{C}$} & $\mathrm{CuO}$ NPs & $\mathrm{CuO}$ NPs & $\mathrm{CuSO}_{4}$ & $\mathrm{CuSO}_{4}$ & PAA & PAA \\
\hline & $0.20 \mathrm{~g} / \mathrm{L}$ & $0.20 \mathrm{~g} / \mathrm{L}$ & $6.60 \mathrm{mg} / \mathrm{L}$ & $6.60 \mathrm{mg} / \mathrm{L}$ & $0.13 \mathrm{~g} / \mathrm{L}$ & $0.13 \mathrm{~g} / \mathrm{L}$ \\
\hline \multirow{2}{*}{$\mathrm{D}$} & $\mathrm{CuO}$ NPs & $\mathrm{CuO}$ NPs & $\mathrm{CuSO}_{4}$ & $\mathrm{CuSO}_{4}$ & PAA & PAA \\
\hline & $0.40 \mathrm{~g} / \mathrm{L}$ & $0.40 \mathrm{~g} / \mathrm{L}$ & $13.16 \mathrm{mg} / \mathrm{L}$ & $13.16 \mathrm{mg} / \mathrm{L}$ & $0.27 \mathrm{~g} / \mathrm{L}$ & $0.27 \mathrm{~g} / \mathrm{L}$ \\
\hline
\end{tabular}

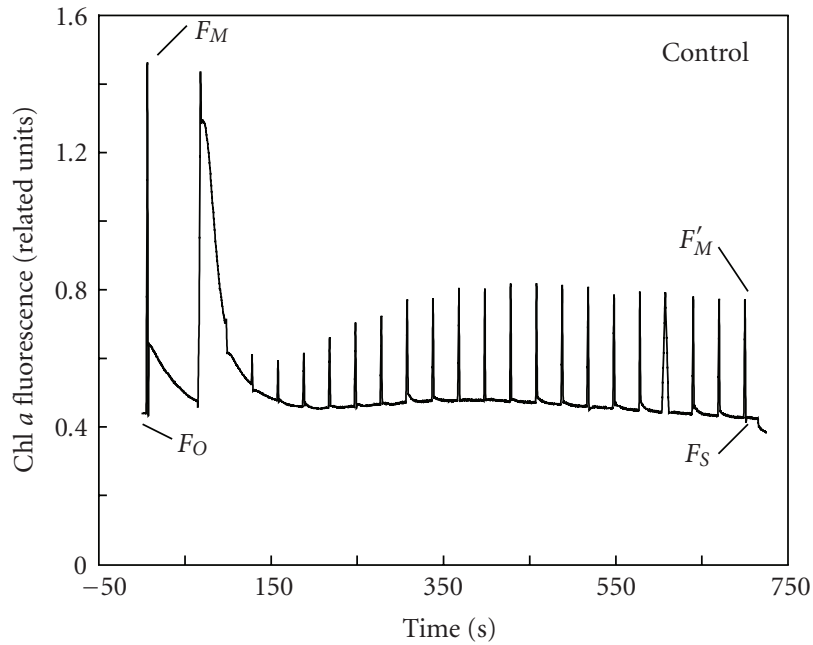

(a)

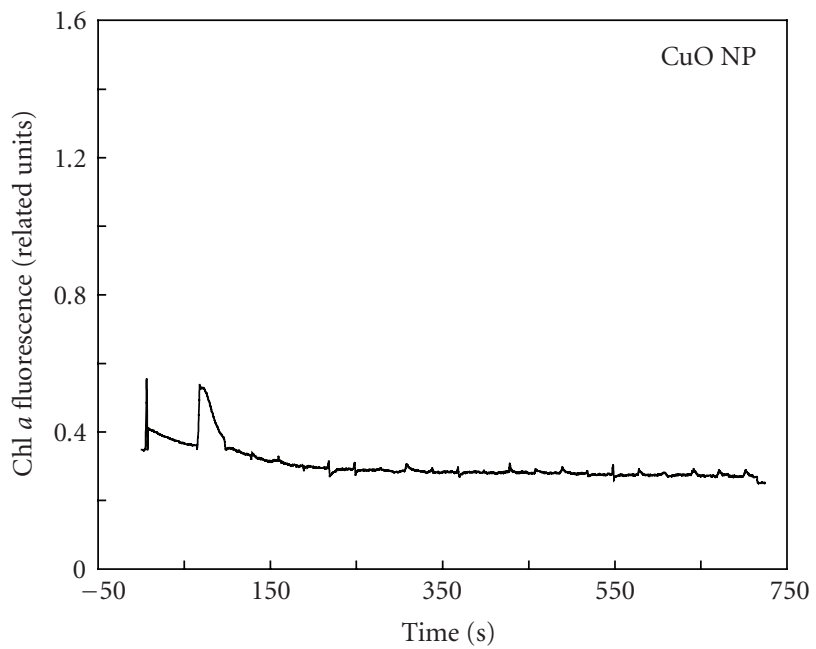

(c)

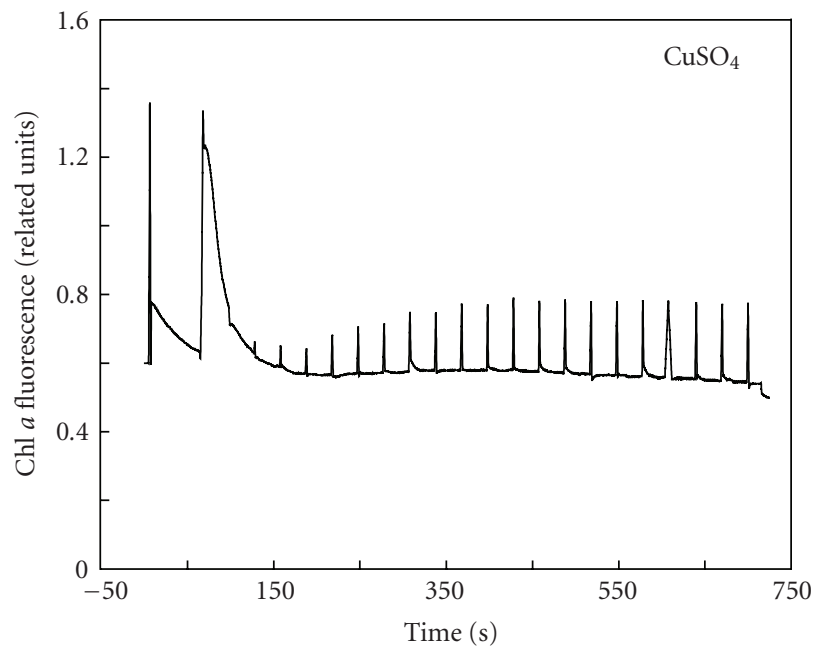

(b)

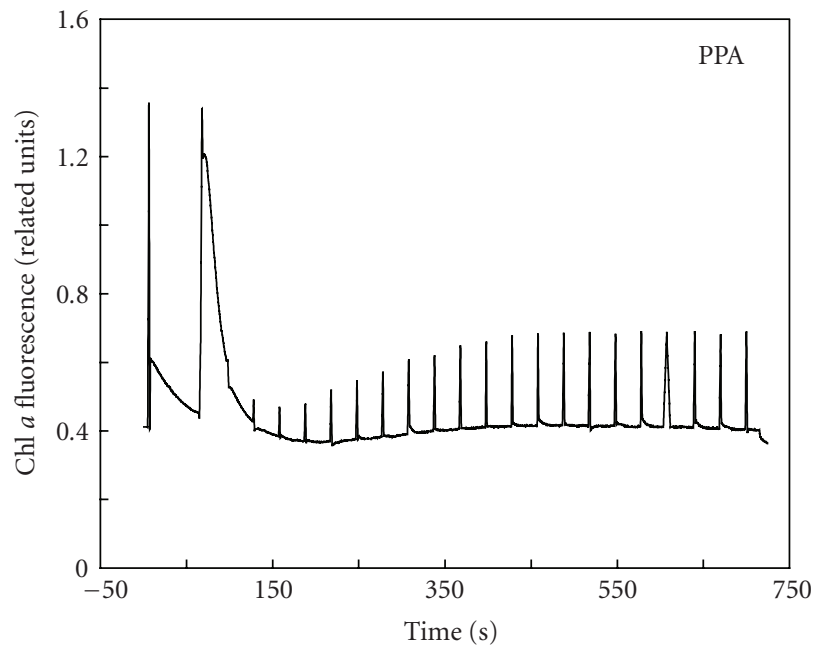

(d)

Figure 2: Change in the Chl $a$ fluorescence kinetics of $L$. gibba leaves exposed 48 hours to $0.4 \mathrm{~g} / \mathrm{L}$ of CuO NPs, its ionic copper fraction alone $\left(13.16 \mathrm{mg} / \mathrm{L} \mathrm{Cu}\right.$ added as $\left.\mathrm{CuSO}_{4}\right)$, and its organic fraction alone $(0.27 \mathrm{~g} / \mathrm{L} \mathrm{PAA})$. For treatments details, see Section 2.

of whole plants, we used Chl $a$ fluorescence imaging method permitting to evaluate the relative value of chlorophyll content based on the evaluation of $F_{O}$ fluorescence value. $L$. gibba plants, exposed separately to treatments in a microplate for $48 \mathrm{~h}$, showed different effect concerning treatments.
Here, imaging of $F_{O}$ fluorescence (indicator of Chl content) showed that $\mathrm{CuO}$ NPs induced strong inhibition of plant growth indicated. Some inhibition by copper ions was also found, while no evident effect of PAA was observed (Figure 1). In L. gibba exposed to those treatments, we 


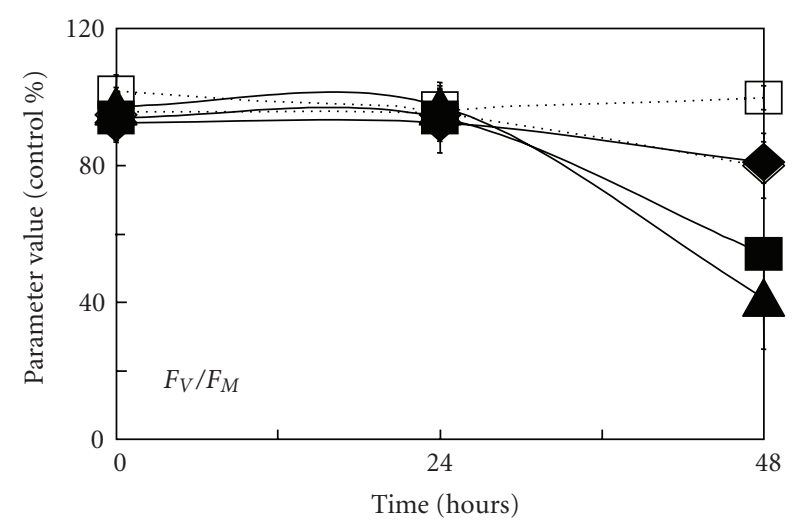

(a)

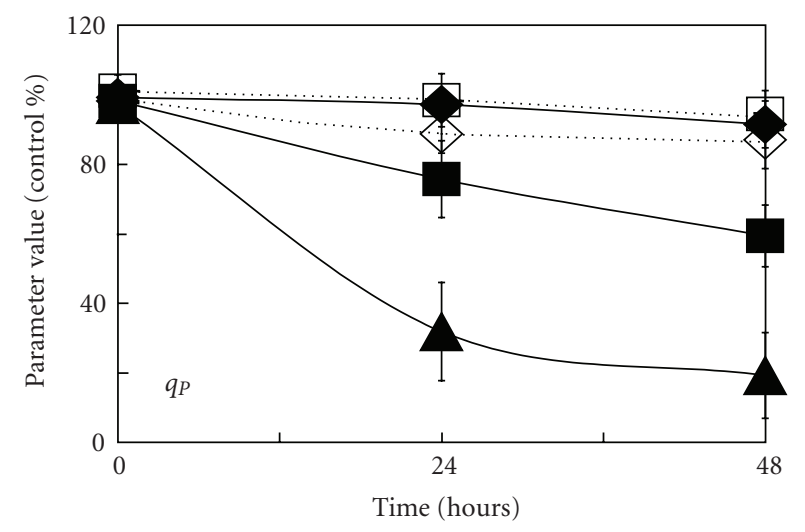

(c)

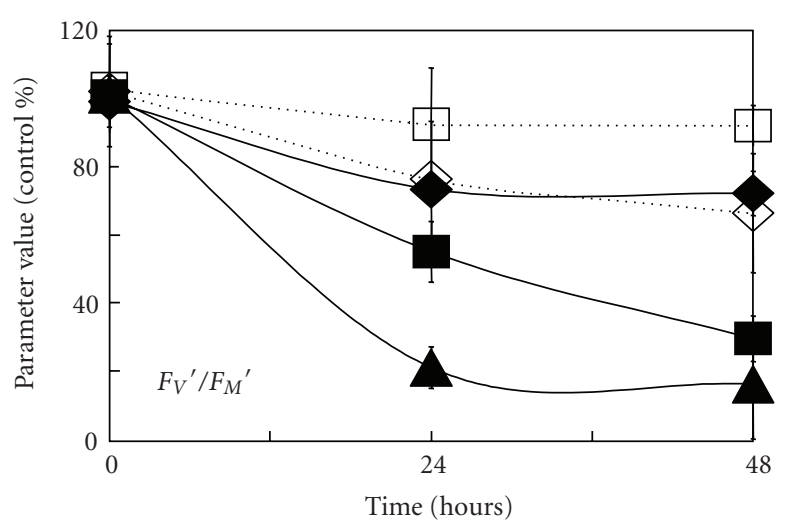

(b)

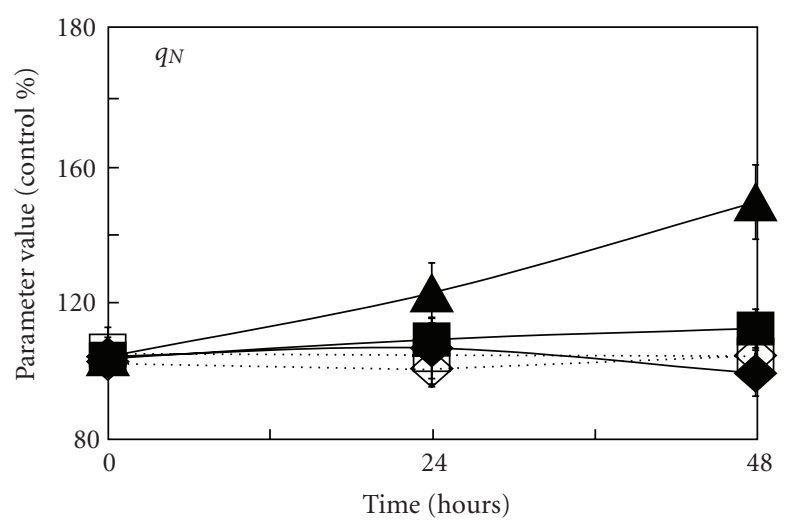

(d)

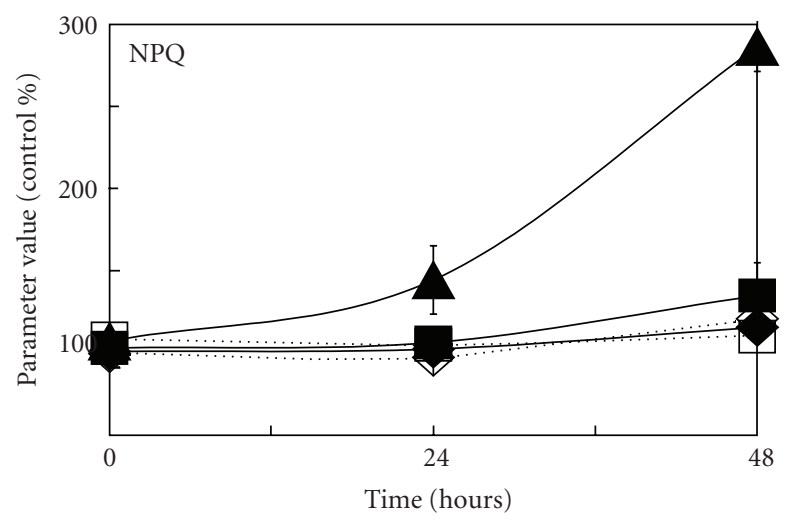

$>\mathrm{CuO}$ NPs $0.1 \mathrm{~g} / \mathrm{L}$

$\mathrm{CuO}$ NPs $0.2 \mathrm{~g} / \mathrm{L}$

$\triangle$ CuO NPs $0.4 \mathrm{~g} / \mathrm{L}$

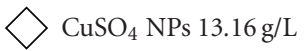

PAA $0.27 \mathrm{~g} / \mathrm{L}$

(e)

FIGURE 3: Change of maximal PSII quantum yield $\left(F_{V} / F_{M}\right)$, operational PSII quantum yield $\left(F_{V}^{\prime} / F_{M}^{\prime}\right)$, photochemical (qP) and nonphotochemical fluorescence quenching coefficient $(q N)$, and the nonphotochemical quenching parameter (NPQ). Different concentrations are indicated by the different symbols on the figure. The error bars indicate the standard deviations calculated on an average of 6 replicates. 
investigated the change of functional photosynthetic state by using the PAM-methodological approach. The change of Chl $a$ fluorescence induction kinetics induced by $10 \mathrm{~min}$ actinic illumination showed high coherence with indications obtained by $F_{O}$ fluorescence imaging. Indeed, maximal PSII fluorescence yield $\left(F_{V} / F_{M}\right.$, in dark adapted fronds) and maximum fluorescence yield of PSII at steady-state of fluorescence (light-adapted at steady-state, $F_{V}^{\prime} / F_{M}^{\prime}$ ) were diminished by the effect of CuO NPs and, to a smaller extent, by copper ions (Figure 2). Those effects imposed the interest to evaluate the alteration of PSII functions caused by such treatments. Here, the change of PSII functional parameters during $48 \mathrm{~h}$ of treatment indicated the modification of PSII energy transfer associated with electron transport and energy dissipation pathways (Figure 3 ). After $48 \mathrm{~h}$ of treatment, maximal quantum yield of PSII $\left(F_{V} / F_{M}\right)$ appeared to be strongly inhibited by $\mathrm{CuO}$ NPs $(41 \pm 15 \%$ of control sample, $P<.05)$. Similar effect was also seen for operational quantum yield $\left(F_{V}^{\prime} / F_{M}^{\prime}\right.$ value of $16 \pm 12 \%$ of control sample for $48 \mathrm{~h} 0.4 \mathrm{~g} / \mathrm{L}$ treated plants, $P<.05)$, while copper ions had some inhibitory effect which was relatively small (66 $\pm 17 \%$ of control sample, $P<.05)$ compared to the effect of $\mathrm{CuO}$ NPs. Some effect of ionic copper can be expected since this metal was previously shown to induce inhibition of the PSII water-splitting system in isolated PSII particles [38]. $\mathrm{Cu}^{2+}$ was also found to increase the sensitivity of leaves to photoinhibition by light and oxidative stress due to its competition with iron as an essential element [39]. Oxidative stress was also found to have a major role in $\mathrm{Cu}^{2+}$ toxicity in photosynthetic organisms [40]. For CuO NPs, a strong production of reactive oxygen species was observed in algal cells exposed under light conditions to $\mathrm{CuO}$ NPs concentrations of $0.02 \mathrm{~g} / \mathrm{L}$ [11]. However, the role of $\mathrm{Cu}^{2+}$ ions in CuO NPs toxicity is still a matter of debate. In some studies, it has been suggested for induced toxicity to be due to the dissolved ionic copper fraction $[36,41]$ while in other reports it has been indicated that ionic copper alone does not explain toxicity induced by $\mathrm{CuO}$ NPs $[42,43]$. Our results concerning the change of $F_{V} / F_{M}$ and $F_{V}^{\prime} / F_{M}^{\prime}$ in L. gibba indicate that $\mathrm{CuO}$ NPs' toxicity was mainly caused by the NPs effect. For such change of PSII quantum yields, we may expect also important change within PSII photochemistry and electron transport associated with energy dissipation through regulated and nonregulated nonphotochemical pathways. Indeed PSII photochemical quenching values were strongly decreased by CuO NPs' effect. Such inhibitory effect altered energy dissipation processes via PSII. It appeared that CuO NPs' effect increased the energy dissipation which is not linked to PSII electron transport. The change of $q N$ value (regulated nonphotochemical energy dissipation) at $48 \mathrm{~h}$ of treatment showed clearly the ability of CuO NPs to decrease drastically absorbed conversion of absorbed light energy via PSII electron transport. Similar and coherent change was found for $\mathrm{CuO}$ NPs' effect on the nonphotochemical quenching parameter based on the Stern-Volmer equation, NPQ (Figure 3).

The use of fluorescence measurements as an indicator of photosynthetic electron transport in whole plants may be associated with some problems since higher plants

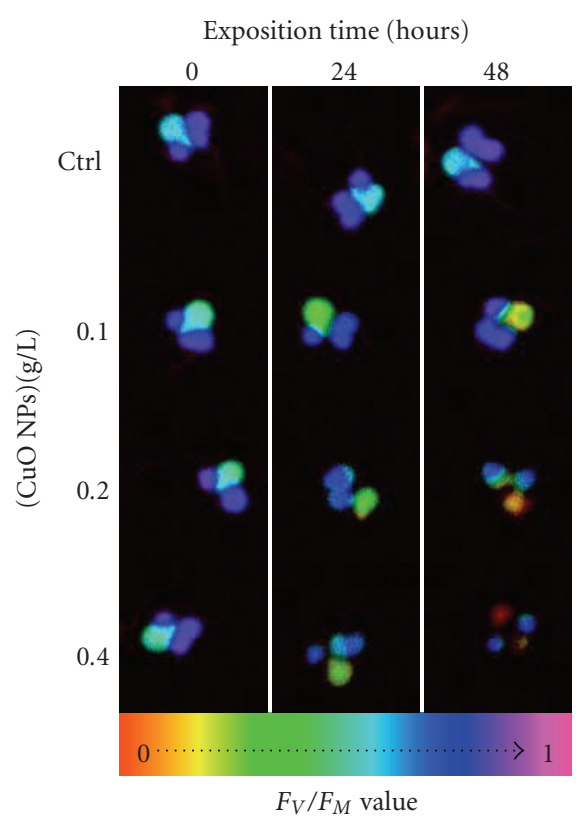

FIGURE 4: The change of the maximal PSII quantum yield $\left(F_{V} / F_{M}\right)$ in $L$. gibba whole plants by being exposed to different concentrations of $\mathrm{CuO}$ NPs, determined by Chl $a$ fluorescence imaging PAM method. CuO NPs' concentrations are indicated on the left side of the figure and exposition time on top of the figure. The change of leaf area and leaf $\mathrm{Chl}$ distribution is indicated on the figure by the change of the size and shape of the fluorescence emission. The change of color on the leaf area in the figure indicates the change of the $F_{V} / F_{M}$ value on this specific leaf area. Color scale on the bottom of the figure indicates the color associated with the relative value $F_{V} / F_{M}$.

show great heterogeneity of leaves concerning physiological development and leaf position [44]. In many cases, for whole plants, it is hard to obtain reproducible results and to get some integral indicator concerning photosynthetic processes. We believe that recent fluorescence imaging methods may give some advantages concerning reproducibility and determination of integral value related to the whole plant. Here, we presented the advantages to use fluorescence imaging methods in the study of pollutant's toxic effects on whole plants. Since microplate has optimal conditions to expose L. gibba plants to different treatments, this approach may provide the possibility to perform multiple synchronous fluorescence measurements of numerous treatments. Furthermore, fluorescence imaging allows to obtain different photosynthetic parameters concerning the integral state of plants. Such approach to measure the inhibitory effect of $\mathrm{CuO} N$ s on $F_{V} / F_{M}$ is presented in Figure 4 . In this figure, for visual presentation, different colors were used to determine the value of photosynthetic parameters distributed on the whole plant. The change of color indicated the heterogeneity of plants but this heterogeneity did not prevent to evaluate the integral value on the whole plant body. Here, we were able, for whole plants, to show the decreased value of $F_{V} / F_{M}$ when plants were exposed $48 \mathrm{~h}$ to $\mathrm{CuO} N P s$. We have to mention that fronds of L. gibba showed a different level 


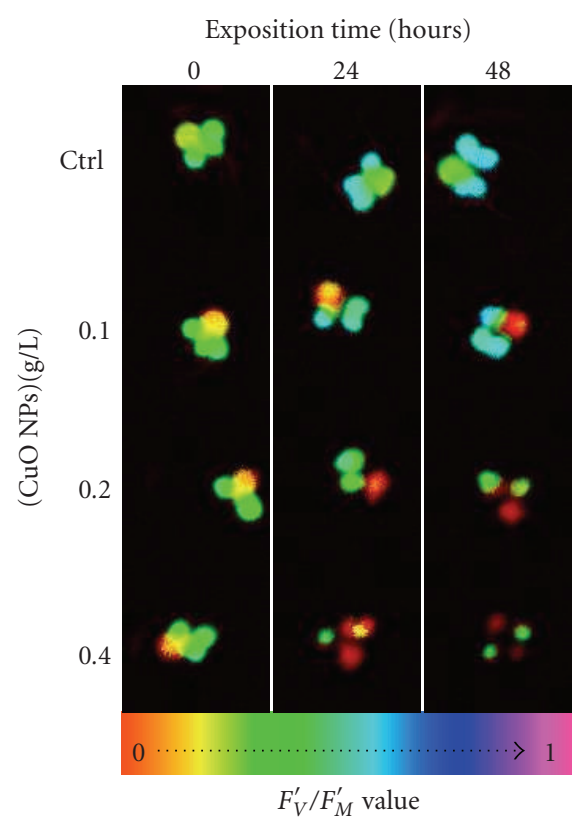

FIgURE 5: The change of the operational PSII quantum yield $\left(F_{V}^{\prime} / F_{M}^{\prime}\right)$ in $L$. gibba whole plants by being exposed to different concentrations of $\mathrm{CuO}$ NPs, determined by Chl $a$ fluorescence imaging PAM method. CuO NPs' concentrations are indicated on the left side of the figure and exposition time on top of the figure. The change of leaf area and leaf $\mathrm{Chl}$ distribution is indicated on the figure by the change of the size and shape of the fluorescence emission. The change of color on the leaf area in the figure indicates the change of the $F_{V}^{\prime} / F_{M}^{\prime}$ value on this specific leaf area. Color scale on the bottom of the figure indicates the color associated with the relative value $F_{V}^{\prime} / F_{M}^{\prime}$.

of inhibition, with some being drastically affected (orange colored) and other at a lesser extent (blue colored) after $48 \mathrm{~h}$ of exposure to $0.4 \mathrm{~g} / \mathrm{L} \mathrm{CuO} \mathrm{NPs.} \mathrm{However,} \mathrm{total} \mathrm{average}$ value of the whole plants was diminished (see Figure 3). Similar conclusions was found for $F_{V}^{\prime} / F_{M}^{\prime}$ (Figure 5). Such results were coherent with the change of parameters obtained from PAM fluorescence kinetics. On Figure 6, a strong increase of nonphotochemical energy dissipation can be seen for the whole plant after $48 \mathrm{~h}$ of exposure to the highest concentration of $\mathrm{CuO}$ NPs. Moreover, the same presentation permitted to indicate a strong decrease of growth for such plants. We believe that no other methods will be able to give such evaluation for numerous samples at the same time. The versatility of this approach and its capacity to provide numerous simultaneous measurements on whole plants indicate that $\mathrm{Chl} a$ fluorescence imaging may be a valuable approach in $\mathrm{CuO}$ NPs' ecotoxicological risk assessment. However, in natural aquatic ecosystems, the degree of contamination by NPs is still hard to evaluate due to the difficulty of quantifying this type of pollutant [45] so we do not know yet the concentrations of nanoparticulate copper that may be encountered in the environment. Using high concentrations on $\mathrm{CuO}$ NPs, L. gibba photosynthetic electron transport was found to be a reliable biomarker

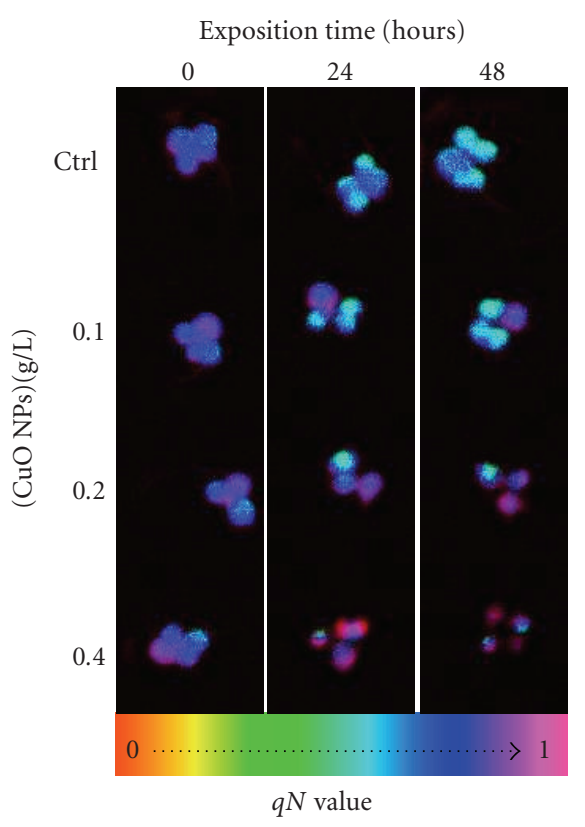

Figure 6: The change of the nonphotochemical quenching of fluorescence $(q N)$ in $L$. gibba whole plants by being exposed to different concentrations of $\mathrm{CuO}$ NPs, determined by $\mathrm{Chl} a$ fluorescence imaging PAM method. CuO NPs' concentrations are indicated on the left side of the figure and exposition time on top of the figure. The change of leaf area and leaf Chl distribution is indicated on the figure by the change of the size and shape of the fluorescence emission. The change of color on the leaf area in the figure indicates the change of the $F_{V}^{\prime} / F_{M}^{\prime}$ value on this specific leaf area. Color scale on the bottom of the figure indicates the color associated with the relative value of $q N$.

for copper NPs' risk assessment, but the sensitivity of this approach remains to be investigated in naturally occurring conditions.

We can conclude that $\mathrm{Chl} a$ fluorescence imaging represents a useful tool to evaluate $\mathrm{CuO}$ NPs effect on photosynthesis in whole plants. These results showed that in microplate conditions, by using treatments and measuring protocol of L. gibba photosynthesis, Chl a fluorescence imaging permitted fast and reliable evaluation of $\mathrm{CuO}$ NPs toxicity for numerous samples. High-repetition measurements may provide rapid evaluation of the risk of toxicity of pollutants in aquatic ecosystems. Such method will allow for further advance research in environmental toxicological studies and bioassays.

\section{Acknowledgments}

This work was supported by the Natural Sciences and Engineering Research Council (NSERC, Canada) grants awarded to R. Popovic. F. Perreault was supported by an NSERC PhD fellowship. The authors would like to thank Pr. Jérôme Claverie for providing the $\mathrm{CuO}$ NPs and PAA solutions. 


\section{References}

[1] R. J. Aitken, M. Q. Chaudhry, A. B. A. Boxall, and M. Hull, "Manufacture and use of nanomaterials: current status in the UK and global trends," Occupational Medicine, vol. 56, no. 5, pp. 300-306, 2006.

[2] A. Dhawan, V. Sharma, and D. Parmar, "Nanomaterials: a challenge for toxicologists," Nanotoxicology, vol. 3, no. 1, pp. $1-9,2009$.

[3] S. K. Brar, M. Verma, R. D. Tyagi, and R. Y. Surampalli, "Engineered nanoparticles in wastewater and wastewater sludge-evidence and impacts," Waste Management, vol. 30, pp. 504-520, 2009.

[4] N. M. Franklin, N. J. Rogers, S. C. Apte, G. E. Batley, G. E. Gadd, and P. S. Casey, "Comparative toxicity of nanoparticulate $\mathrm{ZnO}$, bulk $\mathrm{ZnO}$, and $\mathrm{ZnCl}_{2}$ to a freshwater microalga (Pseudokirchneriella subcapitata): the importance of particle solubility," Environmental Science and Technology, vol. 41, no. 24, pp. 8484-8490, 2007.

[5] E. Navarro, F. Piccapietra, B. Wagner et al., "Toxicity of silver nanoparticles to Chlamydomonas reinhardtii," Environmental Science and Technology, vol. 42, no. 23, pp. 8959-8964, 2008.

[6] M. Kovochich, B. Espinasse, M. Auffan et al., "Comparative toxicity of $\mathrm{C} 60$ aggregates toward mammalian cells: role of tetrahydrofuran (THF) decomposition," Environmental Science and Technology, vol. 43, no. 16, pp. 6378-6384, 2009.

[7] M. Scheringer, "Nanoecotoxicology: environmental risks of nanomaterials," Nature Nanotechnology, vol. 3, no. 6, pp. 322323,2008 .

[8] E. Almeida, T. C. Diamantino, and O. de Sousa, "Marine paints: the particular case of antifouling paints," Progress in Organic Coatings, vol. 59, no. 1, pp. 2-20, 2007.

[9] N. Singh and A. Turner, "Leaching of copper and zinc from spent antifouling paint particles," Environmental Pollution, vol. 157, no. 2, pp. 371-376, 2009.

[10] R. K. Sharma and M. Agrawal, "Biological effects of heavy metals: an overview," Journal of Environmental Biology, vol. 26, no. 2, pp. 301-313, 2005.

[11] C. Saison, F. Perreault, J.-C. Daigle et al., "Effect of core-shell copper oxide nanoparticles on cell culture morphology and photosynthesis (photosystem II energy distribution) in the green alga, Chlamydomonas reinhardtii," Aquatic Toxicology, vol. 96, pp. 109-114, 2009.

[12] D. Dewez, L. Geoffroy, G. Vernet, and R. Popovic, "Determination of photosynthetic and enzymatic biomarkers sensitivity used to evaluate toxic effects of copper and fludioxonil in alga Scenedesmus obliquus," Aquatic Toxicology, vol. 74, no. 2, pp. 150-159, 2005.

[13] S. Knauert and K. Knauer, "The role of reactive oxygen species in copper toxicity to two freshwater green algae," Journal of Phycology, vol. 44, no. 2, pp. 311-319, 2008.

[14] P. Juneau and R. Popovic, "Evidence for the rapid phytotoxicity and environmental stress evaluation using the PAM fluorometric method: importance and future application," Ecotoxicology, vol. 8, no. 6, pp. 449-455, 1999.

[15] P. J. Ralph, R. A. Smith, C. M. O. MacInnis-Ng, and C. R. Seery, "Use of fluorescence-based ecotoxicological bioassays in monitoring toxicants and pollution in aquatic systems: review," Toxicological and Environmental Chemistry, vol. 89, no. 4, pp. 589-607, 2007.

[16] Govindjee, "Sixty-three years since Kautsky: chlorophyll a fluorescence," Australian Journal of Plant Physiology, vol. 22, pp. 131-160, 1995.
[17] N. R. Baker, "Chlorophyll fluorescence: a probe of photosynthesis in vivo," Annual Review of Plant Biology, vol. 59, pp. 89113, 2008.

[18] P. Juneau, B. Qiu, and C. P. Deblois, "Use of chlorophyll fluorescence as a tool for determination of herbicide toxic effect: review," Toxicological and Environmental Chemistry, vol. 89, no. 4, pp. 609-625, 2007.

[19] H. A. Baumann, L. Morrison, and D. B. Stengel, "Metal accumulation and toxicity measured by PAM-Chlorophyll fluorescence in seven species of marine macroalgae," Ecotoxicology and Environmental Safety, vol. 72, no. 4, pp. 1063-1075, 2009.

[20] F. Perreault, N. Ait Ali, C. Saison, R. Popovic, and P. Juneau, "Dichromate effect on energy dissipation of photosystem II and photosystem I in Chlamydomonas reinhardtii," Journal of Photochemistry and Photobiology B, vol. 96, no. 1, pp. 24-29, 2009.

[21] F. Perreault, D. Dewez, C. Fortin, P. Juneau, A. Diallo, and R. Popovic, "Effect of aluminum on cellular division and photosynthetic electron transport in Euglena gracilis and Chlamydomonas acidophila," Environmental Toxicology and Chemistry, vol. 29, no. 4, pp. 887-892, 2010.

[22] M. R. Badger, H. Fallahi, S. Kaines, and S. Takahashi, "Chlorophyll fluorescence screening of Arabidopsis thaliana for $\mathrm{Co}_{2}$ sensitive photorespiration and photoinhibition mutants," Functional Plant Biology, vol. 36, no. 11, pp. 867-873, 2009.

[23] J. D. Scholes and S. A. Rolfe, "Chlorophyll fluorescence imaging as tool for understanding the impact of fungal diseases on plant performance: a phenomics perspective," Functional Plant Biology, vol. 36, no. 11, pp. 880-892, 2009.

[24] A. Küster, K. Pohl, and R. Altenburger, "A fluorescence-based bioassay for aquatic macrophytes and its suitability for effect analysis of non-photosystem II inhibitors," Environmental Science and Pollution Research, vol. 14, no. 6, pp. 377-383, 2007.

[25] U. Schreiber, P. Quayle, S. Schmidt, B. I. Escher, and J. F. Mueller, "Methodology and evaluation of a highly sensitive algae toxicity test based on multiwell chlorophyll fluorescence imaging," Biosensors and Bioelectronics, vol. 22, no. 11, pp. 2554-2563, 2007.

[26] R. Muller, U. Schreiber, B. I. Escher, P. Quayle, S. M. B. Nash, and J. F. Mueller, "Rapid exposure assessment of PSII herbicides in surface water using a novel chlorophyll a fluorescence imaging assay," Science of the Total Environment, vol. 401, no. 1-3, pp. 51-59, 2008.

[27] C. Frankart, P. Eullaffroy, and G. Vernet, "Photosynthetic responses of Lemna minor exposed to xenobiotics, copper, and their combinations," Ecotoxicology and Environmental Safety, vol. 53, no. 3, pp. 439-445, 2002.

[28] J.-C. Daigle and J. P. Claverie, "A simple method for forming hybrid core-shell nanoparticles suspended in water," Journal of Nanomaterials, vol. 2008, no. 1, Article ID 609184, 8 pages, 2008.

[29] U. Schreiber, U. Schliwa, and W. Bilger, "Continuous recording of photochemical and non-photochemical chlorophyll fluorescence quenching with a new type of modulation fluorometer," Photosynthesis Research, vol. 10, no. 1-2, pp. 5162, 1986.

[30] K. Rohacek and M. Bartak, "Technique of the modulated chlorophyll fluorescence: basic concepts, useful parameters, and some applications," Photosynthetica, vol. 37, no. 3, pp. 339-363, 1999. 
[31] K. Oxborough and N. R. Baker, "Resolving chlorophyll a fluorescence images of photosynthetic efficiency into photochemical and non-photochemical components-calculation of qP and Fv-/Fm-; without measuring Fo-;" Photosynthesis Research, vol. 54, no. 2, pp. 135-142, 1997.

[32] M. Kitajima and W. L. Butler, "Quenching of chlorophyll fluorescence and primary photochemistry in chloroplasts by dibromothymoquinone," Biochimica et Biophysica Acta, vol. 376, no. 1, pp. 105-115, 1975.

[33] B. Genty, J. M. Briantais, and N. R. Baker, "The relationship between the quantum yield of photosynthetic electron transport and quenching of chlorophyll fluorescence," Biochimica et Biophysica Acta, vol. 990, pp. 87-92, 1989.

[34] O. van Kooten and J. F. H. Snel, "The use of chlorophyll fluorescence nomenclature in plant stress physiology," Photosynthesis Research, vol. 25, no. 3, pp. 147-150, 1990.

[35] W. Bilger and O. Bjorkman, "Role of the xanthophyll cycle in photoprotection elucidated by measurements of light-induced absorbance changes, fluorescence and photosynthesis in leaves of Hedera canariensis," Photosynthesis Research, vol. 25, no. 3, pp. 173-185, 1990.

[36] I. Blinova, A. Ivask, M. Heinlaan, M. Mortimer, and A. Kahru, "Ecotoxicity of nanoparticles of $\mathrm{CuO}$ and $\mathrm{ZnO}$ in natural water," Environmental Pollution, vol. 158, pp. 41-47, 2009.

[37] L. E. Sverdrup, T. Kallqvist, A. E. Kelley, C. S. Furst, and S. B. Hagen, "Comparative toxicity of acrylic acid to marine and freshwater microalgae and the significance for environmental effects assessments," Chemosphere, vol. 45, no. 4-5, pp. 653658, 2001.

[38] J. B. Arellano, J. J. Lazaro, J. Lopez-Gorge, and M. Barón, “The donor side of Photosystem II as the copper-inhibitory binding site," Photosynthesis Research, vol. 45, no. 2, pp. 127-134, 1995.

[39] E. Patsikka, M. Kairavuo, F. Sersen, E.-M. Aro, and E. Tyystjarvi, "Excess copper predisposes photosystem II to photoinhibition in vivo by outcompeting iron and causing decrease in leaf chlorophyll," Plant Physiology, vol. 129, no. 3, pp. 1359-1367, 2002.

[40] S. Knauert and K. Knauer, "The role of reactive oxygen species in copper toxicity to two freshwater green algae," Journal of Phycology, vol. 44, no. 2, pp. 311-319, 2008.

[41] V. Aruoja, H.-C. Dubourguier, K. Kasemets, and A. Kahru, "Toxicity of nanoparticles of $\mathrm{CuO}, \mathrm{ZnO}$ and $\mathrm{TiO}_{2}$ to microalgae Pseudokirchneriella subcapitata," Science of the Total Environment, vol. 407, no. 4, pp. 1461-1468, 2009.

[42] J. Chen, J. Zhu, H.-H. Cho et al., "Differential cytotoxicity of metal oxide nanoparticles," Journal of Experimental Nanoscience, vol. 3, no. 4, pp. 321-328, 2008.

[43] K. Kasemets, A. Ivask, H.-C. Dubourguier, and A. Kahru, "Toxicity of nanoparticles of $\mathrm{ZnO}, \mathrm{CuO}$ and $\mathrm{TiO}_{2}$ to yeast Saccharomyces cerevisiae," Toxicology in Vitro, vol. 23, no. 6, pp. 1116-1122, 2009.

[44] K. Kitajima, S. S. Mulkey, M. Samaniego, and S. J. Wright, "Decline of photosynthetic capacity with leaf age and position in two tropical pioneer tree species," American Journal of Botany, vol. 89, no. 12, pp. 1925-1932, 2002.

[45] B. M. Simonet and M. Valcarcel, "Monitoring nanoparticles in the environment," Analytical and Bioanalytical Chemistry, vol. 393, no. 1, pp. 17-21, 2009. 

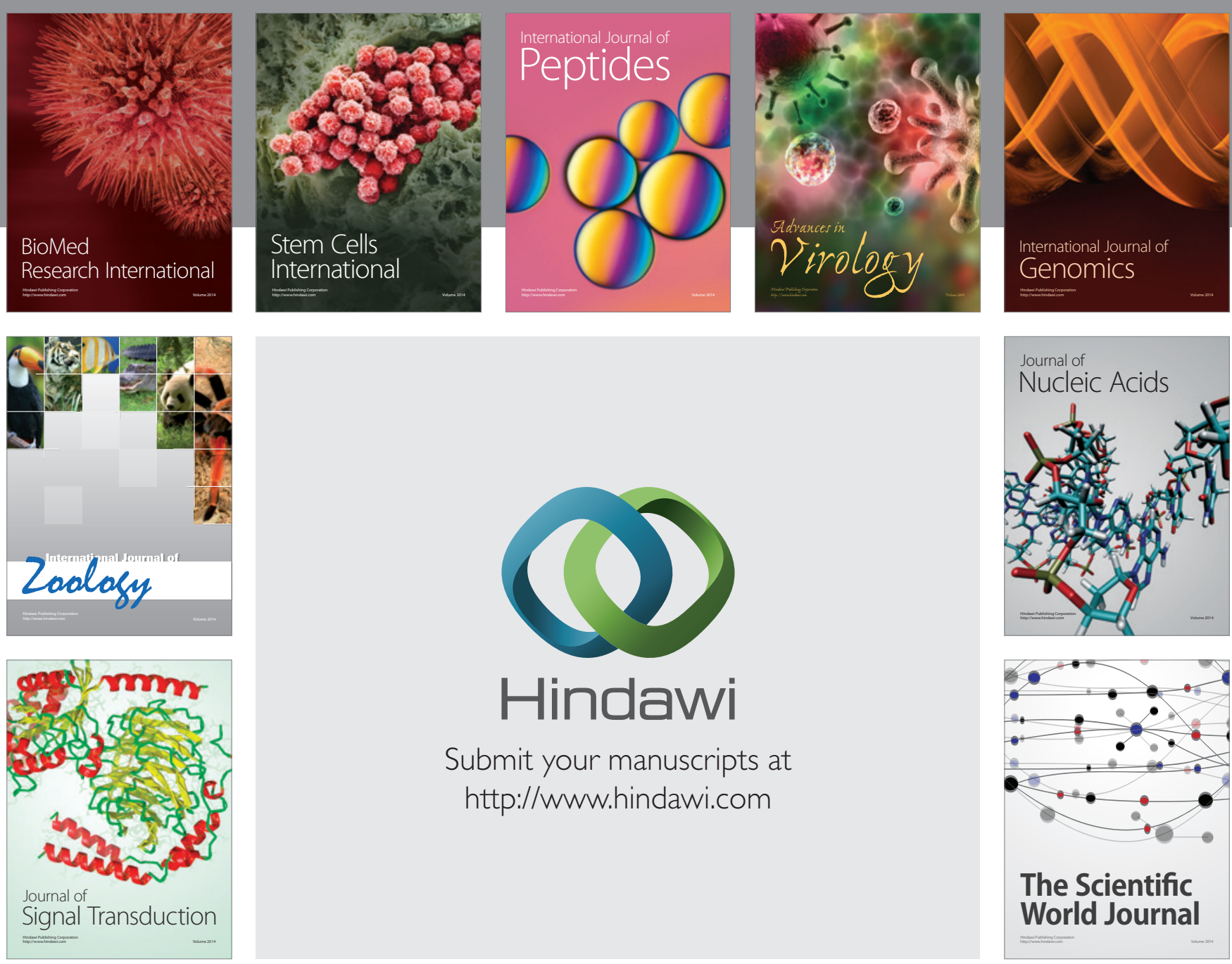

Submit your manuscripts at

http://www.hindawi.com
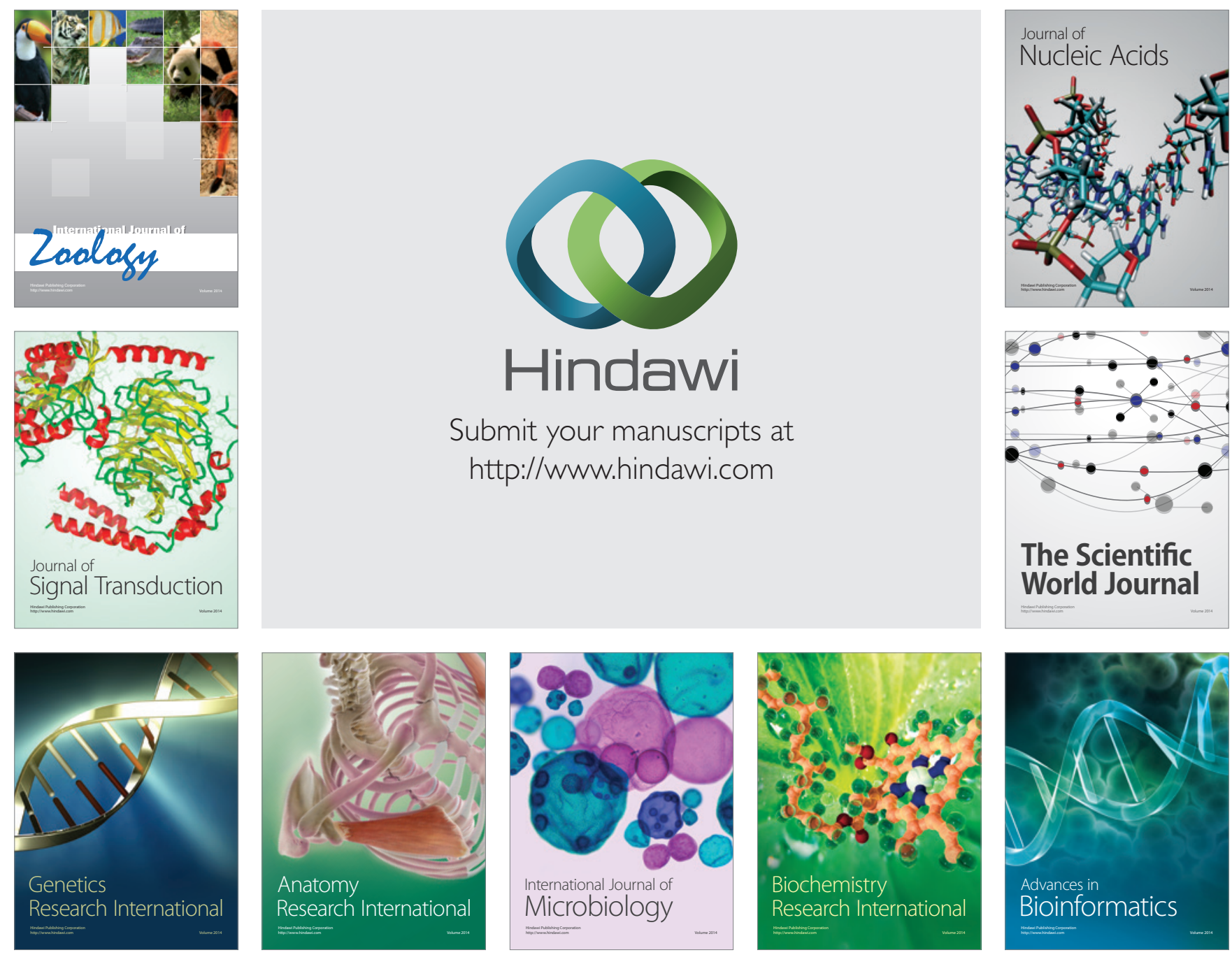

The Scientific World Journal
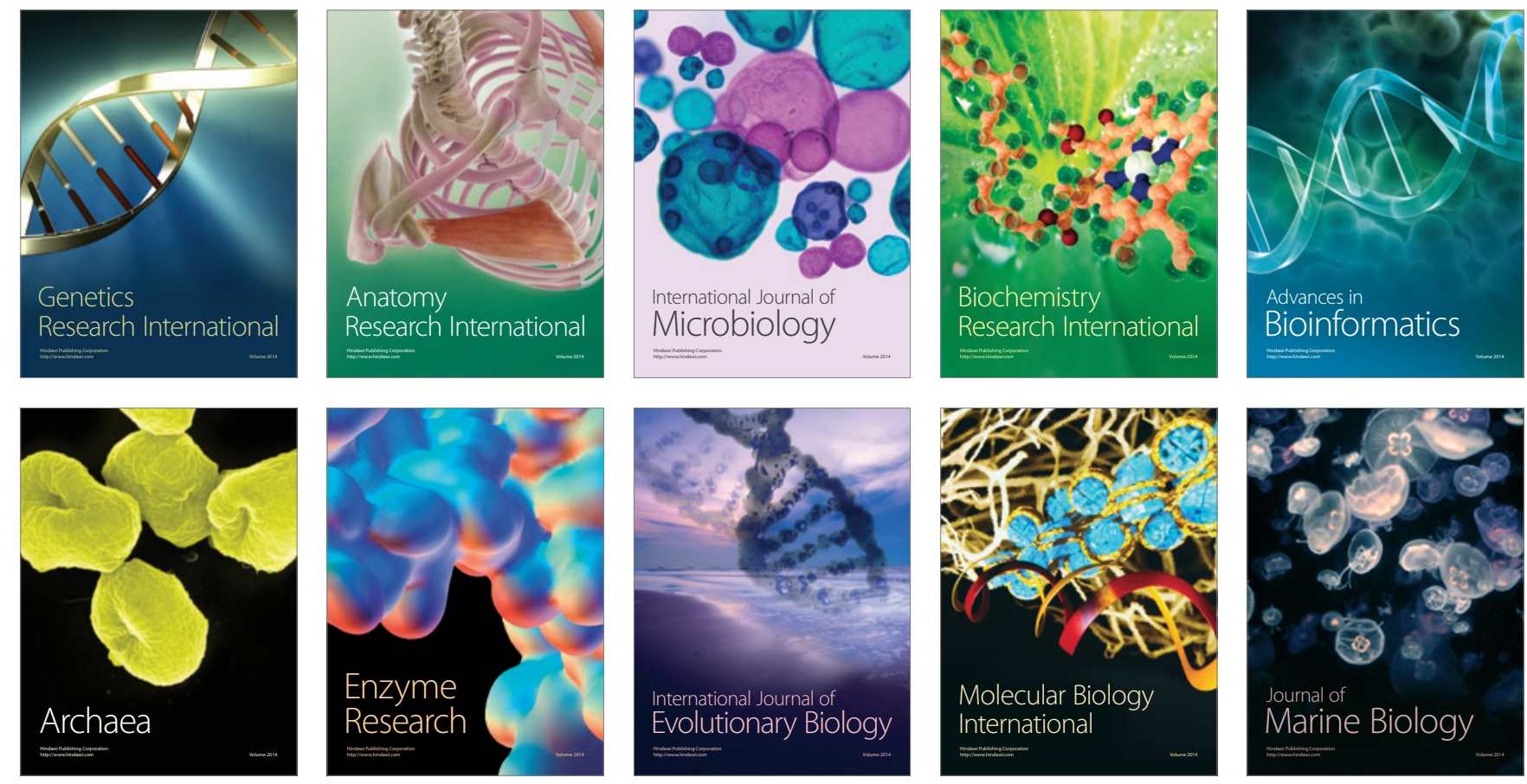